\title{
Comentarios
}

\section{Los indicadores económicos del tercer trimestre 1997}

Una de las posturas más claras por parte de las autoridades económicas de los dos últimos gobiernos ha sido un optimismo desmedido en el momento de realizar la lectura de los indicadores macroeconómicos. La estabilización del tipo de cambio, la reducción de la inflación a cifras por debajo del 10 por ciento, el crecimiento de la producción y las exportaciones, la creciente acumulación de las Reservas Internacionales Netas y la reducción del déficit fiscal han sido noticias muy comunes a lo largo de la presente década. Tan comunes que, incluso, han llegado a restar importancia a dinámicas económicas que sugieren que la estabilidad y el crecimiento se encuentran muy comprometidos por depender de factores exógenos a nuestra economía.

Entre las citadas dinámicas pueden mencionarse: la caída de la participación del sector agropecuario en la producción, los fuertes incrementos en los precios de los alimentos, la participación elevada del consumo en la demanda global, el decrecimiento de las exportaciones tradicionales, la ampliación del déficit de la balanza comercial y del sector público, el incremento de la pobreza extrema rural, etc.

Estos problemas, pese a sus dimensiones y denuncia incansable por diferentes sectores, han sido tratados con relativa indiferencia por las autoridades económicas; ello obedece a que, en la práctica, la presencia de tendencias desequilibrantes ha sido neutralizada con otras fuentes de divisas y consumo. Esta capacidad de maniobra del gobierno obedece, no a su efectividad para diseñar e implemen- tar políticas de estabilización y ajuste económicos, sino más bien al fuerte flujo unilateral de divisas, integrado esencialmente por las remesas familiares. Sólo éstas han evitado el descalabro económico pero, en la actualidad, no han podido evitar un período de recesión económica de casi 2 años.

La reforma económica iniciada en 1990 no ha logrado cumplir con su principal objetivo: convertir las exportaciones en el principal motor del crecimiento y fuente de estabilidad macroeconómica. El crecimiento obedece fundamentalmente a la expansión de la producción no exportable y el consumo generado por las remesas familiares. Sin embargo, esto no ha obstado para que las recientes informaciones del Banco Central de Reserva, al igual que en el pasado, no presten atención a esta deficiencia y se limiten a presentar los elementos positivos de la gestión económica sin contextualizarlos. Una de las consecuencias de esta excesiva confianza en el manejo macroeconómico, podría ser el desperdicio de una importante oportunidad para iniciar un plan de desarrollo económico y social en un contexto de estabilidad macroeconómica.

La señal más clara del agotamiento del modelo de crecimiento económico, practicada durante la presente década, ha sido la abrupta reducción de las tasas de crecimiento económico a partir del segundo semestre de 1995. Aun así, El Salvador es señalado en los círculos del Banco Mundial como un caso exitoso en cuanto a la aplicación de políticas de ajuste estructural. En este marco, interesa analizar los principales indicadores macroeco- 
nómicos del primer trimestre del año para evidenciar que, pese al optimismo que puede desprenderse de las cifras, el panorama económico a mediano plazo, en realidad, se muestra incierto y amenazante.

Un dato que llama la atención del más reciente informe periódico del Banco Central de Reserva, es el incremento en el Índice de Volumen de Actividad Económica durante el pasado mes de febrero, cuando experimentó un ascenso del 0.9 por ciento. A partir de este dato, el presidente de este banco, Roberto Orellana Milla, estimó que "los sectores donde se notan mayores índices de recuperación son la industria, el comercio y la construcción", por lo cual afirma: "creemos que se cumplirá la meta de crecimiento de la economía estimada (en el Programa monetario y financiero) en cuatro por ciento".

Estos datos sugieren que, para el primer trimestre del año, el comportamiento del Producto Interno Bruto fue similar al de 1996, cuando las tasas de crecimiento fueron superiores al 6 por ciento y se obtuvo una de tan sólo 3 por ciento. La principal razón de la reducción del crecimiento ha sido el comportamiento de los sectores agropecuario, industrial, de construcción y comercio. El sector financiero, en cambio, mantiene sus tasas de crecimiento en niveles similares a los observados en años anteriores, es decir, superiores al 15 por ciento. Lo anterior implica que el crecimiento económico ya no es impulsado con la misma intensidad por el sector terciario, en general, sino solamente por el sector financiero.

Respecto a los precios se señala que la inflación acumulada en el mes de marzo pasado fue de 7.4 por ciento, la cual es notablemente inferior a la obtenida en el mismo mes en 1996, que fue del 10.8 por ciento. De acuerdo con el presidente del Banco Central de Reserva, este comportamiento también daría la pauta para esperar "cumplir con la meta propuesta para este año: entre cinco y siete por ciento de inflación". Cabe señalar aquí que, en buena medida, el logro de esta meta está íntimamente ligado al comportamiento de la producción.

Una de las principales causas del descenso en las tasas de crecimiento ha sido la contracción del crédito del sistema financiero al sector privado. medida que fue adoptada por el Banco Central de Reserva, con la finalidad de contener las tendencias inflacionarias que este último generó en 1995 al expandir la demanda agregada. Estas tendencias, aunqu han reducido el crecimiento del Indice de Precios al Consumidor, no han producido efectos importantes sobre los precios del sub-rubro alimentos, cuyo comportamiento supera ampliamente los promedios inflacionarios presentados por el Banco Central de Reserva. Considérese, por ejemplo, que durante el primer trimestre de 1997 . el precio de los rubros misceláneos, vivienda y vestuario se incrementaron en $2.4,1.6$ y 0.04 por ciento, mientras que los precios de los alimentos se incrementaron en 3 por ciento. La tasa de crecimiento del Indice de Precios al Consumidor fue de 2.4 por ciento.

Durante los últimos meses, esta situación se ha reflejado en una variación anual de precios cercana al 12 por ciento, mientras que los sectores vivienda y misceláneos apenas van más allá del 6 por ciento y el de vestuario ni siquiera del 2 por ciento. Así, de no ser por los precios de los alimentos, la tasa inflacionaria apenas rondaría el 4 por ciento.

Desde las actuales condiciones puede sostenerse la existencia de un trade-off entre crecimiento y estabilidad macroeconómica, no sólo por la contracción del crédito con fines antiinflacionarios, sino también por el comportamiento de la balanza comercial, el cual se analiza a continuación.

En el ámbito del sector externo destaca el hecho de que las exportaciones del primer trimestre de 1997 experimentaron un crecimiento del 26.5 por ciento en relación con las exportaciones del mismo período en 1996, con lo cual, de acuerdo con el Banco Central de Reserva, se habría logrado reducir el déficit de la balanza comercial.

Lo cierto es que la verdadera causa de la reducción del déficit en la balanza comercial estriba exclusivamente en la disminución de las importaciones, producto de la reducción de la actividad económica. Así, entre marzo de 1996 y marzo de 1997 ha habido un descenso en el déficit de la balanza comercial, pero no debido a un mayor ritmo en el crecimiento de las exportaciones, sino por la caída de las importaciones. Es importante aclarar que esta situación tiene un agravante, que es la diversificación de las exportaciones, lo cual no sucede en el campo del sector no tradicional. La participación de la maquila en la economía nacional es tal que para 1996 aportó cerca de un $\mathbf{4 0}$ por ciento del total de las exportaciones. 
Lo anterior sugiere que, como se mencionó, el manejo de la economía no ha producido mayores inversiones en la producción de exportaciones, pero sí ha logrado incrementar la producción y las exportaciones generadas a partir de la inversión extranjera, principalmente maquila textil. En buena medida, esta dinámica obedece a dos grupos de factores: por una parte las ventajas que ofrecen los bajos salarios y el marco jurídico de las zonas francas y, por la otra, el mantenimiento del tipo de cambio y el difícil acceso a los mercados internacionales para las exportaciones nacionales. De estos puntos, interesa revisar el comportamiento del tipo de cambio, por ser esta una variable íntimamente ligada al comportamiento del sector externo.

Prácticamente, desde 1993, el tipo de cambio no ha experimentado mayores variaciones, pese a que, desde principios de la década, el gobierno procedió a implementar algunas medidas de reforma económica en el mercado cambiario, tales como la unificación y liberalización del mercado cambiario. En principio, esto suponía un comportamiento acorde con la oferta y demanda de divisas lo cual, dados los flujos crecientes de remesas y el incremento de las Remesas Internaciones $\mathrm{Ne}-$ tas, hacia suponer que el tipo de cambio nominal se reduciría. Sin embargo, debido a las operaciones que el gobierno realiza en el mercado cambiario, éste en realidad se mantiene estable. Ateniéndose a la teoría económica cabría esperar que una reducción en el tipo de cambio nominal vaya en detrimento de la competitividad de las exportaciones, pues ésta es directamente proporcional al tipo de cambio nominal. En cambio, un alza de este último podría traducirse en un incremento de la competitividad.

Lo cierto es que la estabilidad en el tipo de cambio no refleja la situación del mercado cambiario, pero aún así representa un importante apoyo para la estabilización de los precios internos que, lamentablemente, no está siendo capitalizada para impulsar estrategias que incrementen las actividades productivas nacionales.

Otro dato que resalta dentro del informe coyuntural del Banco Central de Reserva es la acumulación creciente de las Remesas Internacionales Netas, al grado que se habría sobrepasado la meta de acumulación contemplada en el Programa monetario y financiero en aproximadamente 25 por ciento, lo cual implicó que, para marzo pasado, se

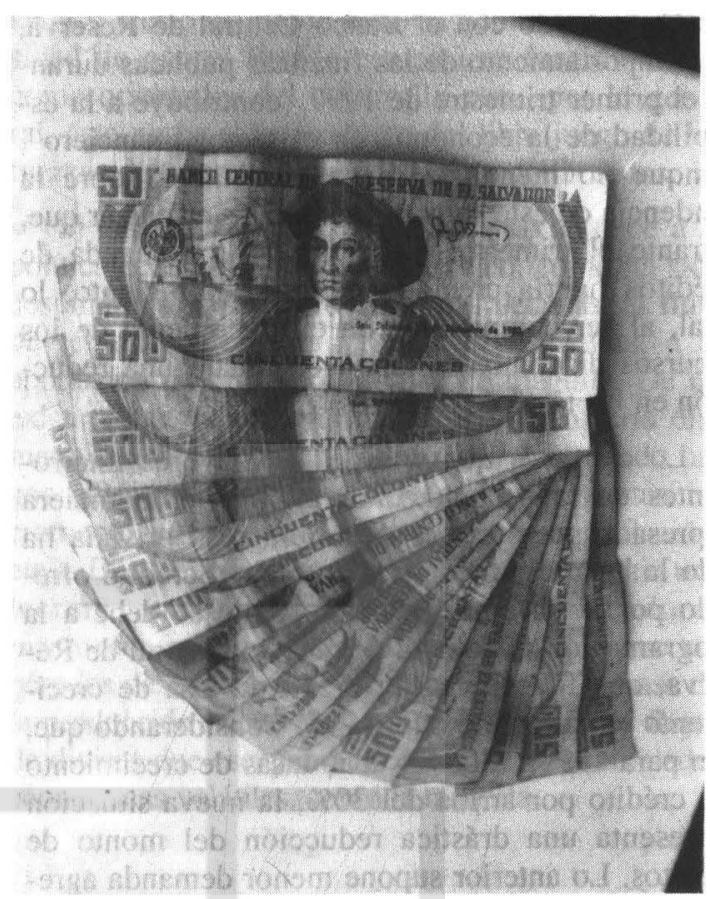

tenía un nivel de Remesas Internaciones Netas de 1,166 millones de dólares. A este respecto siempre resulta paradojico que, a pesar del déficit en la balanza comercial, se estén acumulando estas remesas; la explicación, empero, es simple y se conoce desde la década pasada: la acumulación de divisas provenientes del envío de remesas familiares. Por ser transferencias unilaterales, éstas únicamente causan un efecto positivo sobre la cuenta comiente, no tienen contrapartida. Claramente puede notarse que las remesas, que se espera superen los 1,100 millones de dólares este año, continúan siendo el principal pilar de la estabilización económica.

El comportamiento de las finanzas públicas para el mes de marzo, por su parte, presentarían un superávit que, para el caso del sector público no financiero, habría alcanzado los 297 millones de colones. Esta coyuntura de las finanzas públicas ciertamente da lugar a interpretaciones optimistas, pero no se debe perder la perspectiva de que para 1996, con el incremento de las recaudaciones en concepto de impuesto sobre la renta y el impuesto sobre el valor agregado, el déficit fiscal se incrementó, tanto como proporción del producto interno bruto como en términos absolutos. El hecho de que durante el primer trimestre se obtuviera un superávit fiscal no garantiza que para finales de año esta situación se mantenga. 
De acuerdo con el Banco Central de Reserva, el comportamiento de las finanzas públicas durante el primer trimestre de 1997 "contribuye a la estabilidad de la economía en el sector financiero", aunque no menciona mayores detalles sobre la tendencia de este sector, limitándose a señalar que, durante el trimestre mencionado, la demanda de créditos habría crecido en un 17 por ciento, lo cual, al ser compatible con el crecimiento de los recursos disponibles, habría originado una reducción en las tasas de interés.

Lo cierto es que una de las mayores interrogantes de la programación monetario financiera expresada por sectores de la empresa privada ha sido la baja tasa de crecimiento en el crédito ofrecido por el sistema financiero. Esto se debe a la programación financiera del Banco Central de Reserva, que fija en 14 por ciento la tasa de crecimiento en el crédito para 1997. Considerando que, aún para 1995, se observaban tasas de crecimiento del crédito por arriba del $30 \%$, la nueva situación representa una drástica reducción del monto de créditos. Lo anterior supone menor demanda agregada y menores presiones sobre los precios, pero a costa de una reducción en el crecimiento económico, especialmente en relación con los niveles observados antes de 1995.

Otro elemento que es importante destacar, aunque no se encuentra dentro de los datos presentados por el Banco Central de Reserva, es el comportamiento de los salarios mínimos y del empleo. Desde 1995 no se han efectuado ajustes salariales, lo cual, al conjugarse con el constante incremento del nivel general de precios, ha sobredeterminado el hecho de que los salarios estén constantemente perdiendo su valor. Así, desde el último incremento en los salarios mínimos nominales, los salarios mínimos reales (es decir, los salarios mínimos nominales deflatados por los precios) han perdido aproximadamente un 10 por ciento de su valor.

Las estadísticas sobre el comportamiento del empleo son algunas de las omisiones más notorias en los informes del banco. Sin embargo, a partir de datos alternativos como la inscripción de afiliados al Instituto Salvadoreño del Seguro Social, presentadas por el mismo BCR, puede establecerse que las tendencias en el ámbito urbano son hacia el incremento del desempleo. Por ejemplo, para 1996, el número de afíliados al ISSS - con cobertura esencialmente urbana- crecio en solamente un décimo de lo que lo hizo la Población
Económicamente Activa urbana.

El panorama recién descrito da una idea de la situación coyuntural de la economía salvadoreña: reducción en el crecimiento económico, la participación de la agricultura y del empleo; la disminución de las tasas inflacionarias y del déficit comercial a costa de la contracción del crédito y del crecimiento; en el incremento de las Remesas Internaciones Netas gracias al flujo de remesas familiares; en el descenso de los salarios reales, etc.

En realidad, pues, el panorama no es alentador. El reporte trimestral del Banco Central de Reserva refleja que, afortunadamente, aún permanece el flujo de remesas familiares e, incluso, las exportaciones de maquila que permiten mantener la estabilidad de la macroeconomía, pero esta situación no puede perdurar ni siquiera a mediano plazo, tanto por la volatibilidad de la inversión en la maquila como por la existencia de múltiples condicionamientos para el envío de remesas (migración de todo el grupo familiar, rompimiento de vínculos, etc.), y porque existe la amenaza de expulsión de un importante porcentaje de salvadoreños residentes en los Estados Unidos $y$, por tanto, se suspenda el envío de sus remesas. De hecho, durante los últimos meses, y contrariamente a las versiones de funcionarios estadounidenses, el flujo de salvadoreños deportados se ha incrementado en forma importante.

A este nivel del ajuste, el país aún no logra definir sectores económicos estratégicos que permitan un incremento sostenido en la producción, el empleo y las exportaciones; lo cual es necesario para crear bases endógenas para la estabilidad macroeconómica y el incremento de producción, empleo e ingresos. La atrofia del aparato productivo nacional resulta especialmente cuestionable porque se ha dado en un contexto de abundancia de recursos. En este momento existe la posibilidad de articular una estrategia de fomento de sectores estratégicos en un escenario de estabilidad económica posibilitado por las remesas familiares.

En este marco podrían formularse al menos cinco recomendaciones de política económica que hagan frente, no sólo a la coyuntura económica, sino también a otros problemas de larga data.

1. Implementación de un programa de asistencia técnica y crediticia para los sectores agropecuario e industrial. Lo anterior, incluso, no implicaría un incremento en el crédito sino solamente una reorientación del mismo. 
2. Desarollo de estrategias antiinflacionarias dirigidas a disminuir especialmente los precios de los alimentos.

3. Reducción de la evasión fiscal para mejorar las recaudaciones tributarias y el sempiterno problema del déficit fiscal.

4. Estructuración de una estrategia alternativa para la promoción de las exportaciones, fundamentada en la diversificación de la producción exportable, y el aprovechamiento y búsqueda de tratados comerciales favorables

5. Implementación de una estrategia de fijación del salario mínimo que garantice, tal como el Código de Trabajo lo establece, la satisfacción de las necesidades básicas.

Como se puede inferir, la posibilidad de superar los avatares para el desarrollo necesariamente requieren una redefinición de las relaciones comerciales con los países desarrollados. Sin la apertura de mercados basada en la reciprocidad, no se puede tener éxito al pretender estimular el crecimiento de las exportaciones agrícolas o industria- les. Lo cierto es que la historia demuestra la necesidad de que el Estado asuma una función fuerte como orientador del desarrollo pues, por lo general, éste no ha sido producto del libre juego de las fuerzas del mercado sino de planes deliberados.

Si existe estabilidad económica no se debe a la política económica del gobierno sino, como ha sido costumbre durante las dos últimas décadas, al flujo de remesas familiares $y$, en menor medida, a la aportación de las exportaciones de maquila. De no existir estas, la situación de la economía sería diametralmente diferente (déficit de la balanza de pagos, pérdida de las remesas intemacionales netas, incremento en el tipo de cambio, mayor inflación, etc.). Ello debería mover al gobierno a asumir una lectura más crítica de los indicadores macroeconómicos y diseñar una estrategia que supere los desequilibrios permanentes sobre la base de la producción nacional, y no sobre la base de flujos de divisas que escapan a su control o de actividades económicas volátiles, como la maquila.

Luis. E. Romano 